\title{
Extremely Low Birth Weight Predisposes to Impaired Renal Health: A Pooled Analysis
}

\author{
Maja Gilarska ${ }^{a} \quad$ Anke Raaijmakers ${ }^{b, c}$ Zhen-Yu Zhang ${ }^{d}$ Jan A. Staessen ${ }^{d}$ \\ Elena Levtchenkob,c Małgorzata Klimek ${ }^{a}$ Andrzej Grudzieńa \\ Katarzyna Starzec ${ }^{a}$ Karel Allegaert ${ }^{\text {b, e }}$ Przemko Kwinta ${ }^{a}$ \\ aDepartment of Pediatrics, Jagiellonian University Medical College, Cracow, Poland; \\ ${ }^{b}$ Department of Development and Regeneration, University of Leuven, Leuven, Belgium; \\ 'Department of Pediatrics, University Hospitals Leuven, Leuven, Belgium; ${ }^{\mathrm{d} D e p a r t m e n t}$ \\ of Cardiovascular Sciences, Studies Coordinating Centre, Research Unit Hypertension and \\ Cardiovascular Epidemiology, University of Leuven, Leuven, Belgium; ' Intensive Care and \\ Department of Pediatric Surgery and Department of Pediatrics, Division of Neonatology, \\ Erasmus MC Sophia Children's Hospital, Rotterdam, The Netherlands
}

\section{Keywords}

Extremely low birth weight $\cdot$ Cystatin $C \cdot$ Renal complications $\cdot$ Hypertension

\begin{abstract}
Background: A number of studies examined the association between preterm delivery and kidney size and function later in life. However, the number of cases in published cohort studies is low. This study was aimed at performing a multicenter collaboration to pool data to obtain more accurate results to quantify the extent of renal impairment in former extremely low birth weight (ELBW; $<1,000 \mathrm{~g})$ children. Methodology: We performed a subject-level metaanalysis to pool data from Cracow (64 cases/34 controls) and Leuven (93 cases/87 controls). We assessed and analyzed cystatin C, estimated glomerular filtration rate (eGFR), ultrasound kidney length, and blood pressure (BP) in 11-year-old ELBW children compared with controls born at term. The prevalence of hypertension (HT) and prehypertension (preHT) in both groups was also analyzed. Results: The study group comprised 157 former ELBW children (gestational age 23-33 weeks and birth weight 430-1,000 g) and 123 children born at term. Former ELBW children had lower mean eGFR (100.62 \pm 16.53 vs. $111.89 \pm 15.26 \mathrm{~mL} / \mathrm{min} / 1.73$ $\left.\mathrm{m}^{2} ; p<0.001\right)$, smaller absolute kidney length ( $8.56 \pm 0.78$ vs. $\left.9.008 \pm 0.73 \mathrm{~cm} ;<0.001\right)$, and higher systolic (111.8 \pm 9.8 vs. $107.2 \pm 9.07 \mathrm{~mm} \mathrm{Hg} ; p=0.01)$ and diastolic ( $68.6 \pm 6.8$ vs. 66.3 $\pm 7.7 \mathrm{~mm} \mathrm{Hg} ; p=0.03$ ) BP. Smaller renal size in former ELBW children was positively associated with lower birth weight, shorter gestational age, and severity of perinatal complications (intraventricular hemorrhage, length of stay, mechanical ventilation, and oxygen therapy).
\end{abstract} Conclusion: ELBW is associated with lower eGFR and a high frequency of preHT and HT. 


\section{Kidney \\ Blood Pressure \\ Research}

\begin{tabular}{|c|c|}
\hline \multicolumn{2}{|c|}{ Kidney Blood Press Res 2019;44:897-906 } \\
\hline DOI: $10.1159 / 000502715$ & $\begin{array}{l}\text { (c) } 2019 \text { The Author(s). Published by S. Karger AG, Basel } \\
\text { www.karger.com/kbr }\end{array}$ \\
\hline
\end{tabular}

Gilarska et al.: Extremely Low Birth Weight Predisposes to Impaired Renal Health A Pooled Analysis

\section{Introduction}

Organogenesis of the kidney is an ongoing developmental process that continues until 34-36 weeks of gestation. In an autopsy study [1], it was observed that the radial glomerular counts were significantly decreased in preterms when compared to controls. Also, Sutherland et al. [2] showed that renal maturation accelerates after preterm birth with an increased number of glomerular generations. Moreover, these preterm kidneys had a greater percentage of morphologically abnormal glomeruli and a significantly larger cross-sectional area of the renal corpuscle. Another issue is that many preterms are also exposed to hypoxia, hyperoxia, nephrotoxic medications, acute kidney injury, and poor extrauterine nutrition - risk factors associated with impaired renal development. These observations suggest that kidneys of children born prematurely may be more vulnerable to impaired renal function later in life. The relative risk of developing chronic kidney disease from childhood into mid-adulthood after preterm birth has recently been quantified and was highest (3-fold) in former extreme preterm birth ( $<28$ weeks) children [3].

Along this line, pooling of data in former growth-restricted preterm neonates is even more relevant.

Multiple studies reported on cystatin $\mathrm{Clevel}$ and the corresponding estimated glomerular filtration rate (eGFR) values throughout the pediatric life in former extremely low birth weight (ELBW; $<1,000 \mathrm{~g}$ ) cohorts [4-11]. However, the number of cases in published cohort studies is low and multicenter collaboration to pool data together to obtain more accurate results, preferably throughout pediatric life and beyond, is crucial.

In the last decades, a lot of studies showing that hypertension (HT) occurs more often in former preterm infants were published. Lurbe et al. [12] proved that significantly higher blood pressure (BP) values are measured after the first month of LBW children life. Furthermore, higher BP is determined more strongly by birth parameters than by any anthropometric measurement [13].

In 2013-2018, 2 groups of investigators (from Children Hospital in Cracow and University Hospital of Leuven) independently analyzed the impact of ELBW on renal size and function, as well as on BP parameters in 11-year-old former preterms $[8,14,15]$. Due to the fact that sample size, both in mentioned studies and other available publications, was not sufficient, a collaborative effort was undertaken to merge the data.

This study was aimed at pooling the currently published data on renal outcome in 11-year-old former ELBW and age-matched children born at term to obtain more accurate results. The hypothesis was that children born prematurely have lower eGFR, decreased kidney length, and higher BP when compared to term controls.

\section{Materials and Methods}

A subject-level meta-analysis was performed to pool data from Cracow and Leuven cohorts of 11-year-old former ELBW into a single database. Detailed methodology was described in previous publications of the Cracow [14] and Leuven [16] research groups. Both methodology and methods of harmonization are also presented in the article supplement. In both centers, all children born with ELBW between 2002 and 2004 (Cracow) and between 2000 and 2005 (Leuven) were invited to participate in the study at the age of 11 years. In Cracow, 91 former ELBW cases were invited, of which 64 participated (70\%). In Leuven, of the 140 children invited, 93 participated (66.4\%). Control groups in both centers consisted of age-matched children born at term. In Cracow, 34 controls were recruited from one general practice office. In Leuven, controls were either friends of the cases $(n=41)$ or recruited at an elementary school close to the examination center $(n=46)$. 


\section{Kidney \\ Blood Pressure \\ Research}

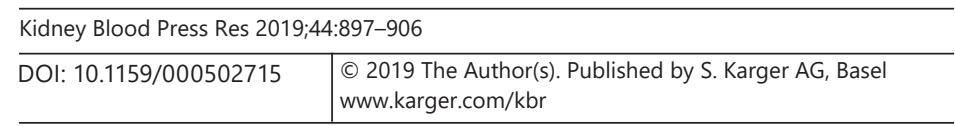

Gilarska et al.: Extremely Low Birth Weight Predisposes to Impaired Renal Health: A Pooled Analysis

\section{Anthropometric Measurements at 11 Years}

In both Cracow and Leuven cohorts, body height was measured to an accuracy of $1 \mathrm{~mm}$. Body weight was measured to an accuracy of $100 \mathrm{~g}$ with calibrated scales. Data were presented as absolute values and z-scores (calculated on the basis of the WHO Growth Reference Data, 2007). Body surface area was calculated using the formula BSA $=0.024265 \times$ height $(\mathrm{cm})^{0.3964}$ $\times$ weight $(\mathrm{kg})^{0.5378}[17]$.

\section{BP Measurements at 11 Years}

In Cracow, the Spacelabs Healthcare device model 92017 was used to perform $24 \mathrm{~h}$ ambulatory BP measurements. In Leuven, BP was the average of 3 consecutive auscultatory readings obtained according to European guidelines with a standard mercury sphygmomanometer after the children had rested in the sitting position for at least $5 \mathrm{~min}$. To compare data of Leuven cohort with Cracow group, the average of 3rd, 4th, and 5th single ambulatory BP measurement measurements were extracted from the device report. Prehypertension (preHT) and HT were defined as BPs exceeding the 90th and 95th percentiles of the distributions stratified according to sex, age, and body height [18]. Absolute values of BP were also converted into percentiles using the norms published in 2010 [19].

\section{Serum Cystatin C Level and eGFR}

In Cracow, cystatin $\mathrm{C}$ was measured by a particle-enhanced immunonephelometric assay (NLatex Cystatin C assay; Dade Behring, Deerfield, IL, USA) using a nephelometer (BN-II; Dade Behring). In Leuven, cystatin $C$ was measured by a particle-enhanced immunoturbidimetric Tina-quant ${ }^{\circledR}$ CysC Generation 2 assay on a COBAS Integra 400 system. To compare the results, Cracow cohort results were transferred using the formula $y=0.937 x+0.231$ [20]. The normal value for children between 4 and 12 years of age was defined as $0.53-0.95 \mathrm{mg} / \mathrm{L}$.

The glomerular filtration rate was estimated using the Caucasian-Asian-Pediatric-Adult formula [21]:

$$
\mathrm{eGFR}\left(\mathrm{mL} / \mathrm{min} / 1.73 \mathrm{~m}^{2}\right)=130 \times \text { cystatin }^{-1.069} \times \operatorname{age}^{-0.117}-7 .
$$

\section{Kidney Ultrasound}

For each child, the kidney length was calculated as the average of 3 (Cracow) or 2 (Leuven) measurements. Renal measurements were performed with the children lying in supine position, and the largest longitudinal distance in the sagittal plane was measured.

The reference values of kidney length were calculated using the formula of Dinkel et al. [22]. Renal length was adjusted to the patient's height. The formulae used to calculate the predicted renal length were:

Left kidney $(\mathrm{mm}): 0.51346 \times$ height $(\mathrm{cm})+17.659$

Right kidney $(\mathrm{mm}): 0.49915 \times$ height $(\mathrm{cm})+18.381$

The formula used to calculate the relative kidney length was:

Relative kidney length = (actual kidney length measured by ultrasound/predicted kidney length) $\times 100 \%$

Kidney was assumed to be too small when relative kidney length was $<85 \%$ of the predicted value. This definition was chosen because $15 \%$ decrease of renal size is approximately the deviation of $(-1)$ Z-score.

\section{Primary Outcomes}

1 Decrease of eGFR estimated on the basis of cystatin $\mathrm{C}$ below $90 \mathrm{~mL} / \mathrm{min} / 1.73 \mathrm{~m}^{2}$

2 Prevalence of preHT or HT 
Table 1. Measurements at birth and at 11 years in cases and controls

\begin{tabular}{lllllc}
\hline Measurements at birth & Cases & & Controls & & p value \\
\hline Gestational age, weeks, mean \pm SD & 27.37 & 2.04 & 39.34 & 1.41 & $<\mathbf{0 . 0 0 1}$ \\
Child birth weight, g, mean \pm SD & 814 & 138 & 3,447 & 515 & $<\mathbf{0 . 0 0 1}$ \\
Gender, girls/boys, $n$ & $89 / 68$ & & $62 / 61$ & 0.33 \\
Birth weight small/accurate for GA, $n$ & $55 / 101$ & & $6 / 110$ & $\mathbf{0 . 0 0 1}$ \\
\hline Measurements at 11 years & & & & & \\
Body height, cm, mean \pm SD & 143.7 & 8.9 & 148.4 & 9.8 & $<\mathbf{0 . 0 0 1}$ \\
Body height (Z-score) & -0.49 & 0.96 & 0.42 & 0.99 & $<\mathbf{0 . 0 0 1}$ \\
Body weight, kg & 35.3 & 9.0 & 40.6 & 9.6 & $<\mathbf{0 . 0 0 1}$ \\
Body weight (Z-score) & -0.157 & 1.36 & 0.457 & 1.18 & $<\mathbf{0 . 0 0 1}$ \\
Head circumference, cm & 50.8 & 2.0 & 53.1 & 1.5 & $<\mathbf{0 . 0 0 1}$ \\
Head circumference (Z-score) & -2.489 & 1.44 & -0.964 & 1.00 & $<\mathbf{0 . 0 0 1}$ \\
Body surface area, mean \pm SD & 1.18 & 0.18 & 1.28 & 0.19 & $<\mathbf{0 . 0 0 1}$ \\
\hline
\end{tabular}

Figures in bold indicate significance.

\section{Secondary Outcomes}

Absolute and relative kidney length, serum cystatin C level, estimated GFR, absolute BP values, and BP percentiles.

\section{Statistical Analysis}

For database management and statistical analysis, we used SPSS software, version 24 (IBM, Armonk, NY, USA). We compared means by Student $t$ test or Mann-Whitney U test, as appropriate, and proportions by the Fisher's exact test. Multivariable-adjusted linear regression was used to analyze the association of kidney size with other risk factors. The presence of preHT and HT was analyzed using logistic regression. Significance was a 2 -sided $p$ value smaller than 0.05 .

\section{Results}

\section{Population}

The study group comprised 157 former ELBW children (gestational age from 23 to 33 weeks) with a birth weight of 430-1,000 g. The control group consisted of 123 children born full-term (gestational age from 37 to 44 weeks) with a birth weight of 2,040-5,000 g. The mean age at the time of examination was $11.6 \pm 1.1$ years in the group of children born prematurely and $11.2 \pm 1.2$ years in control group $(p=0.022)$. Table 1 lists the measurements obtained at birth in cases and controls.

\section{Anthropometric Measurements}

Children born prematurely were $4.7 \mathrm{~cm}$ shorter than children born at term $(143.7 \pm 8.9$ vs. 148.4 $\pm 9.8 ; p<0.01)$. The difference remained after conversion to Z-scores $(-0.49 \pm 0.96$ vs. $0.42 \pm 0.99 ; p<0.01$ ). Moreover, preterm children were $5.1 \mathrm{~kg}$ lighter and had $2.3 \mathrm{~cm}$ smaller head circumference than controls ( $35.3 \pm 9.0$ vs. $40.6 \pm 9.6 ; p<0.001$ and $50.8 \pm 2.0$ vs. $53.1 \pm 1.5 ; p<0.001$, respectively).

\section{Estimated Glomerular Filtration Rate}

The level of cystatin $C$ was available in 123 former ELBW children (78\%) and 107 controls (87\%). Reasons for the unavailability of blood samples were refusal of the child $(n=10)$, too 
Table 2. Primary outcomes in cases and controls

\begin{tabular}{|c|c|c|c|c|c|}
\hline & \multicolumn{2}{|c|}{ Cases } & \multicolumn{2}{|c|}{ Controls } & \multirow[t]{2}{*}{$p$ value } \\
\hline & $n$ & $\%$ & $n$ & $\%$ & \\
\hline High serum cystatin C level $>0.95 \mathrm{mg} / \mathrm{L}$ & 54 & 43.9 & 15 & 14.0 & $<0.001$ \\
\hline GFR $<90 \mathrm{~mL} / \mathrm{min} / 1.73 \mathrm{~m}^{2}$ & 35 & 28.7 & 10 & 9.3 & $<0.001$ \\
\hline \multicolumn{6}{|l|}{ Blood pressure } \\
\hline$<90$ pc & 82 & 58.2 & 84 & 71.8 & 0.048 \\
\hline $90-95 \mathrm{pc}$ & 22 & 15.6 & 9 & 7.7 & \\
\hline$>95 \mathrm{pc}$ & 37 & 26.2 & 24 & 20.5 & \\
\hline
\end{tabular}

GFR, glomerular filtration rate. Figures in bold indicate significance.

Table 3. Secondary outcomes in cases and controls

\begin{tabular}{|c|c|c|c|c|c|}
\hline & \multicolumn{2}{|l|}{ Cases } & \multicolumn{2}{|c|}{ Controls } & \multirow[t]{2}{*}{$p$ value } \\
\hline & mean & SD & mean & SD & \\
\hline Cystatin C, mg/L & 0.932 & 0.133 & 0.847 & 0.102 & $<0.001$ \\
\hline $\mathrm{eGFR}, \mathrm{mL} / \mathrm{min} / 1.73 \mathrm{~m}^{2}$ & 100.62 & 16.53 & 111.89 & 15.26 & $<0.001$ \\
\hline Mean SBP, mm Hg & 111.8 & 9.8 & 107.2 & 9.07 & $<0.001$ \\
\hline Mean DBP, mm Hg & 68.6 & 6.8 & 66.3 & 7.7 & 0.03 \\
\hline SBP, pc & 60.3 & 27.2 & 50.5 & 28.4 & 0.01 \\
\hline $\mathrm{DBP}, \mathrm{pc}$ & 74.1 & 21.7 & 64.8 & 27.6 & 0.003 \\
\hline Absolute left kidney length, $\mathrm{cm}$ & 8.56 & 0.75 & 9.009 & 0.73 & $<0.001$ \\
\hline Relative left kidney length & 0.93 & 0.069 & 0.96 & 0.068 & 0.004 \\
\hline Absolute right kidney length, $\mathrm{cm}$ & 8.56 & 0.80 & 9.007 & 0.73 & $<0.001$ \\
\hline Relative right kidney length & 0.95 & 0.076 & 0.97 & 0.069 & 0.005 \\
\hline
\end{tabular}

eGFR, estimated glomerular filtration rate; SBP, systolic blood pressure; DBP, diastolic blood pressure. Figures in bold indicate significance.

low sample volume $(n=12)$ or inability to collect blood after 1 or 2 attempts $(n=28)$. The mean eGFR in the ELBW group was $100.6 \pm 16.5 \mathrm{~mL} / \mathrm{min} / 1.73 \mathrm{~m}^{2}$, whereas in controls 111.9 $\pm 15.3 \mathrm{~mL} / \mathrm{min} / 1.73 \mathrm{~m}^{2}(p<0.001)$. eGFR was below $90 \mathrm{~mL} / \mathrm{min} / 1.73 \mathrm{~m}^{2}$ in 35 children born prematurely $(28.7 \%)$ and in 10 children in the control group $(9.3 \%) ; p<0.01$.

\section{Blood Pressure}

BP data were available in 141 ELBW children (89.8\%) and in 117 children born at term (95.1\%). Both systolic (SBP) and diastolic (DBP) BP were significantly higher in the ELBW group. The difference was present in both absolute values (SBP $111.8 \pm 9.8$ vs. $107.2 \pm 9.07$ $\mathrm{mm} \mathrm{Hg} ; p=0.01$; DBP $68.6 \pm 6.8$ vs. $66.3 \pm 7.7 \mathrm{~mm} \mathrm{Hg} ; p=0.03$ ), as well as in percentiles (SBP $60.3 \pm 27.2$ vs. $50.5 \pm 28.4 ; p=0.01$; DBP $74.1 \pm 21.7$ vs. $64.8 \pm 27.6 ; p=0.003$ ). The prevalence of preHT and HT was higher in prematurely born children. Twenty two (15.6\%) ELBW children displayed preHT and an additional $37(26.2 \%)$ had HT. In the control group, this was $9(7.7 \%)$ and 24 (20.5\%), respectively; $p=0.048$.

\section{Renal Size}

Renal ultrasound was performed in 150 (95.5\%) children born prematurely and in 120 $(97.6 \%)$ children born at term. Both the absolute and relative kidney lengths were shorter in 


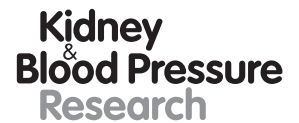

Research

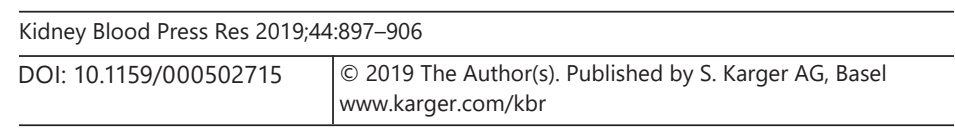

Gilarska et al.: Extremely Low Birth Weight Predisposes to Impaired Renal Health: A Pooled Analysis

the group of prematurely born children. However, relative kidney length $<85 \%$ of normal value was found in 19 (12.7\%) ELBW and in 7 (5.8\%) controls; $p=0.06$.

Multivariable logistic regression revealed that independent risk factors of decreased kidney size are gestational age and center (Cracow/Leuven). For every additional week of gestational age, the probability of low relative kidney length decreased by about $28.8 \%$ (OR 0.712 ).

All primary and secondary data are presented in Tables 2 and 3.

\section{Differences between Cracow and Leuven Patients}

The main difference between Cracow and Leuven cohorts is the type of hospitalized patients. Leuven premature infants, due to specific hospital requirement (advanced perinatology center), were referred to or treated in one facility. Cracow cohort consisted of 2 equal parts. About $53 \%$ of children were born and treated at the University Hospital in Cracow and Tarnów Hospital, while the others were treated at the University Children's Hospital and were out-born patients (delivered in smaller hospitals, with less experience in premature perinatal care).

The percentage of girls was higher in Cracow cohort (67.2 vs. $49.5 \%$ in Leuven; $p=0.033$ ). Leuven cohort was 0.78 years older than Cracow $(11.09 \pm 0.41$ vs. $11.87 \pm 1.35 ; p<0.001)$ at assessment. The duration of hospitalization did not differ significantly between cities and cohorts' weight gain (Cracow: $22.6 \pm 15.7$ vs. Leuven: $17.4 \pm 4.5 \mathrm{~g}$ /day; $p=0.22$ ). Children from Cracow had $1.9 \mathrm{~cm}$ smaller head circumference compared to those from Leuven. The difference between groups in absolute values of height was shown (141.7 \pm 7.9 vs. $145.1 \pm$ 9.3; $p=0.014$ ), but it was statistically insignificant after recalculation into percentiles. Body weight was similar in both groups.

There were no differences between cities in gestational age, percentage of SGA (small for gestational age), and postnatal administration of steroids. In the Cracow cohort, the birth weight was higher compared to the Leuven cohort ( $843 \pm 132$ vs. $795 \pm 138 ; p=0.028$ ). Moreover, 10 patients from the Cracow group received below 5 points in Apgar scale in 5 th min of life, compared to 0 children from the Leuven group $(p<0.001)$. Less children from Cracow needed PDA treatment (29.7 vs. 49.5\%; $p=0.02$ ); however, the frequency of intraventricular hemorrhage was higher in this group (66.7 vs. $22.8 \% ; p<0.001$ ). The prenatal administration of steroids was higher in Leuven (89\%) than in Cracow (48.4\%); $p<0.001$. The duration of mechanical ventilation in Cracow was longer compared to Leuven (median 21 vs. 7 days; $p=0.008$ ) and patients required oxygen for a longer time period (median 51 vs. 37 days; $p<0.001$ ). As a result, the frequency of BPD was higher in the Cracow cohort.

\section{Discussion}

Our pooled analysis confirmed that children born with ELBW have smaller renal size, poorer kidney function as estimated by CysC clearance, and elevated BP when compared to controls who were 11 years old. We hereby quantified the incidence of these events, and analyzed the relevance of potential risk factors (gestational age, disease severity).

Seven publications assessing the levels of cystatin c/CysC-eGFR in former preterms, published after 2010, were available on PubMed [4-11]. Most authors focused on the first 1-3 years of life [4-6, 10], only 2 papers investigated 11-year-old children [8, 11]. Moreover, comparison to a term-born control group was found only in 5 of those studies $[4,6-8,11]$. Cystatin C was chosen for GFR estimation, because eGFR based on CysC levels has been shown to be superior to eGFR based on creatinine [23]. The risk of eGFR decrease in premature children was widely discussed in the literature in the last decades. Most studies confirm renal 
Kidney

Blood Pressure

Research

Fig. 1. Speculations about age-related decline in GFR in healthy peers and predicted values of GFR in age-matched former ELBW cases. eGFR, estimated glomerular filtration rate; ELBW, extremely low birth weight.

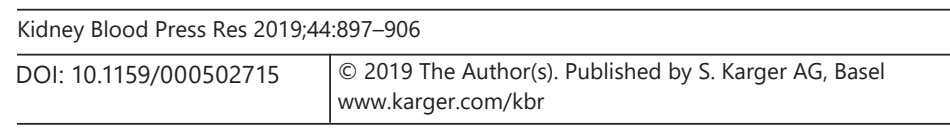

Gilarska et al.: Extremely Low Birth Weight Predisposes to Impaired Renal Health: A Pooled Analysis

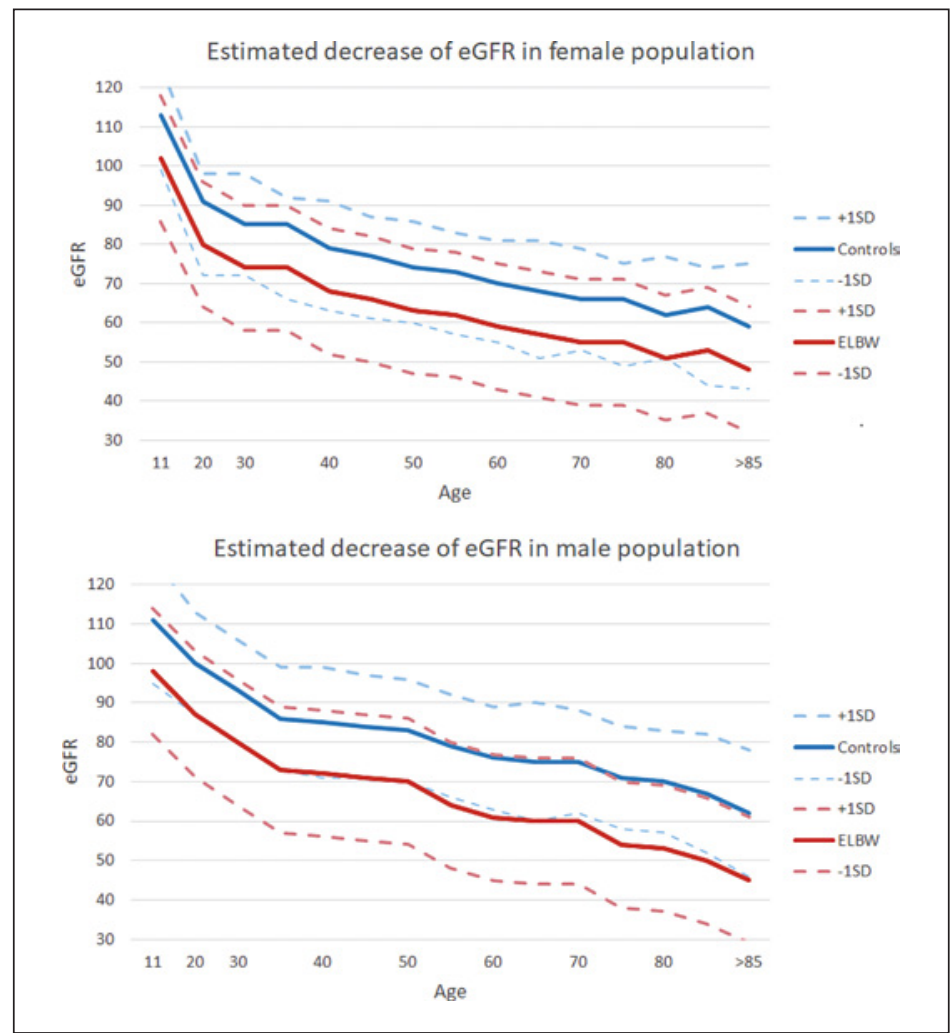

function impairment in preterms (compared to controls): 44 babies at 38 weeks of gestational age [4], 60 children between 12 and 36 months [6], 48 children at the age of 8.3 years [7], 40 children at the age of 8.6 years [24]. However, Rakow et al. [25] found no significant differences in renal function between preterm and term groups small and appropriate for gestational age. We confirmed in a large combined cohort that children born prematurely are at greater risk of decreased eGFR. This fact is crucial due to the work published by Davies and Shock, which confirmed the concept of age-related decline in GFR - among apparently healthy adults there was a linear decline of GFR beyond the age of 30 years, such that by age 90 years, GFR was reduced by an average of $46 \%$ from that found in youth [26].

Although speculative, we combined the data from Davis and Shock with the CracowLeuven data collected from healthy 11-year-old controls to create a graph (separately for male and female populations) reflecting the anticipated decrease of eGFR throughout life. We subsequently used the same trend line on decrease to the mean eGFR in our study group of former ELBW preterms (Fig. 1). In doing so, we presented the average decline of GFR in healthy peers, compared to ELBW children. We can speculate that due to prematurity, the decrease of eGFR below $60 \mathrm{~mL} / \mathrm{min} / 1.73 \mathrm{~m}^{2}$ will be diagnosed 20 years earlier in ELBW than their healthy peers. Moreover, it seems that almost in 1 of 5 ex-preterms 2 nd stage chronic kidney disease will be diagnosed between 30 and 40 year of life. Although based on extrapolation, this decrease of renal function is clinically important and indicates that perinatal history should be taken into consideration by nephrologists in assessing the risk of chronic kidney disease in their patients and is a topic for clinical research [27].

Another important issue in former ELBW cases is an increased risk of cardiovascular diseases, firstly hypothesized by Barker et al. [28]. Over the last decades, many authors reported on the BP elevation of former preterm-born children. It has been proven that birth 


\section{Kidney \\ Blood Pressure \\ Research}

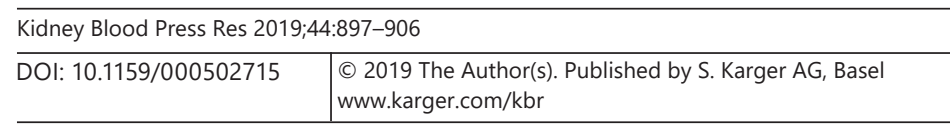

Gilarska et al.: Extremely Low Birth Weight Predisposes to Impaired Renal Health: A Pooled Analysis

characteristics determine BP values stronger than any other parameter [13]. Most studies concentrate on absolute values of BP and show significantly higher SBP [29-36] and elevated DBP values [32, 35-37] in this group. HT diagnosis in the context of prematurity is rarely mentioned [38]. In the presented population, we assessed SBP, DBP as well as the prevalence of preHT and HT, indicating that ELBW is strongly correlated with changes in BP profile.

Furthermore, decrease in renal size in prematurely born children was observed. Similar data were reported after examination of: 44 newborns in 38th week of post menstruation age [4], 69 prematurely born 5-year-old children [9], and 51 young adults [39].

We proved that the probability of small kidney diagnosis is higher in children from Cracow than in children from Leuven. There was no difference in controls' absolute and relative kidney size between cities. The difference in relative kidney length between cities is, in our opinion, associated with the characteristics of the cohorts.

The heterogeneity of presented ELBW population is one of the main strengths, as well as, limitation of the study. The strength of this study is that we merged data from 2 neonatology tertiary centers to analyze the renal size, function, and BP in premature children later in life. Moreover, in both cities only preterms with ELBW were enrolled in the study and assessment was made at the same age of about 11 years. All data were collected and pooled into a single database. As a result of this merge, we constructed the biggest available dataset to assess the impact of ELBW on further renal outcomes and BP. An obvious next step is to merge more datasets with different characteristics (gestational age, weight, treatment modalities) with subsequent assessment of renal outcome throughout pediatric life and beyond. Analyzed population contained both in-born and out-born patients, as well as children born in high and middle income countries. We suspect that the presented results are independently correlated to prematurity and ELBW. However, a high percentage of in-born children (whose mothers received steroids prenatally) might indicate that in children born in "emergency" delivery, outcomes could be much poorer than presented. The significant value of our study is also that data were converted into Z-scores, percentiles, and relative values. This is very important in the assessment of pediatric population.

The main limitation of this study is the difference in measurement methodology. All raw data were converted in the best possible way, but some differences are inevitable due to the retrospective design of the present study.

In summary, we confirmed that premature birth of children with ELBW, as well as indicators of disease severity during perinatal care, have crucial influence on the future life of these children. Renal size decrease, kidney function deterioration, and BP elevation are frequently observed in former ELBW. Moreover, our study suggests that even mild deterioration of kidney function in teenagers may have substantial effect on the probability of chronic kidney disease in later life. We have also shown that BP elevation is associated with premature birth.

In our opinion, it is essential for all specialists to consider that nowadays more and more former ELBW children become adults, burdened with the risk of - among others - renal or cardiovascular complications. Most of these complications are still mild in early adulthood, but become remarkable after years of deterioration.

\section{Statement of Ethics}

Subjects' parents or guardians have given their written informed consent. The Ethical Committee of Jagiellonian University, Krakow (Poland) and The Ethics Committee of the University Hospitals Leuven (Belgium) approved the study. 


\section{Kidney \\ Blood Pressure \\ Research}

\begin{tabular}{l|l}
\hline Kidney Blood Press Res 2019:44:897-906 \\
\hline DOI: 10.1159/000502715 & $\begin{array}{l}\text { @ 2019 The Author(s). Published by S. Karger AG, Basel } \\
\text { www.karger.com/kbr }\end{array}$ \\
\hline
\end{tabular}

Gilarska et al.: Extremely Low Birth Weight Predisposes to Impaired Renal Health: A Pooled Analysis

\section{Disclosure Statement}

The authors have no conflicts of interest relevant to this article.

\section{Author Contributions}

K.A.: study concept and design. M.G., A.R., Z.-Y.Z., E.L., M.K., A.G., and K.S.: acquisition of data. M.G., K.A., P.K.: analysis and interpretation of data. M.G.: drafting of the manuscript. J.A.S., K.A., P.K., A.R., Z.-Y.Z., E.L., M.K., A.G., K.S.: critical revision of the manuscript for important intellectual content. M.G., P.K.: statistical analysis. K.A., P.K., J.A.S.: study supervision.

\section{References}

1 Rodríguez MM, Gómez AH, Abitbol CL, Chandar JJ, Duara S, Zilleruelo GE. Histomorphometric analysis of postnatal glomerulogenesis in extremely preterm infants. Pediatr Dev Pathol. 2004 Jan-Feb;7(1):17-25.

2 Sutherland MR, Gubhaju L, Moore L, Kent AL, Dahlstrom JE, Horne RS, et al. Accelerated maturation and abnormal morphology in the preterm neonatal kidney. J Am Soc Nephrol. 2011 Jul;22(7):1365-74.

3 Crump C, Sundquist J, Winkleby MA, Sundquist K. Preterm birth and risk of chronic kidney disease from childhood into mid-adulthood: national cohort study. BMJ. 2019 May;365:11346.

4 Kandasamy Y, Smith R, Wright IM, Lumbers ER. Extra-uterine renal growth in preterm infants: oligonephropathy and prematurity. Pediatr Nephrol. 2013 Sep;28(9):1791-6.

5 Frankfurt JA, Duncan AF, Heyne RJ, Rosenfeld CR. Renal function and systolic blood pressure in very-lowbirth-weight infants 1-3 years of age. Pediatr Nephrol. 2012 Dec;27(12):2285-91.

6 Carballo-Magdaleno D, Guízar-Mendoza JM, Amador-Licona N, Domínguez-Domínguez V. Renal function, renal volume, and blood pressure in infants with antecedent of antenatal steroids. Pediatr Nephrol. 2011 Oct; 26(10):1851-6.

7 Yamamura-Miyazaki N, Yamamoto K, Fujiwara K, Santo Y, Michigami T, Kitajima H, et al. Risk factors associated with a decreased estimated glomerular filtration rate based on cystatin C levels in school-age children with extremely low birthweight. Nephrology (Carlton). 2017 Jun;22(6):463-9.

8 Raaijmakers A, Zhang ZY, Claessens J, Cauwenberghs N, van Tienoven TP, Wei FF, et al. Does Extremely Low Birth Weight Predispose to Low-Renin Hypertension? Hypertension. 2017 Mar;69(3):443-9.

9 Zaffanello M, Brugnara M, Bruno C, Franchi B, Talamini G, Guidi G, et al. Renal function and volume of infants born with a very low birth-weight: a preliminary cross-sectional study. Acta Paediatr. 2010 Aug;99(8):1192-8.

10 Nakashima T, Inoue H, Fujiyoshi J, Matsumoto N. Longitudinal analysis of serum cystatin C for estimating the glomerular filtration rate in preterm infants. Pediatr Nephrol. 2016 Jun;31(6):983-9.

11 Kwinta P, Klimek M, Drozdz D, Grudzień A, Jagła M, Zasada M, et al. Assessment of long-term renal complications in extremely low birth weight children. Pediatr Nephrol. 2011 Jul;26(7):1095-103.

12 Lurbe E, Cifkova R, Cruickshank JK, Dillon MJ, Ferreira I, Invitti C, et al. Management of high blood pressure in children and adolescents: recommendations of the European Society of Hypertension. J Hypertens. 2009 Sep; 27(9):1719-42.

13 Lurbe E, Garcia-Vicent C, Torro I, Fayos JL, Aguilar F, de Llano JM, et al.: First-year blood pressure increase steepest in low birthweight newborns. J Hypertens. 2007 Jan;25(1):81-6.

14 Starzec K, Klimek M, Grudzień A, Jagła M, Kwinta P. Longitudinal assessment of renal size and function in extremely low birth weight children at 7 and 11 years of age. Pediatr Nephrol. 2016 Nov;31(11):2119-26.

15 Gilarska M, Klimek M, Drozdz D, Grudzien A, Kwinta P. Blood Pressure Profile in the 7th and 11th Year of Life in Children Born Prematurely. Iran J Pediatr. 2016 May 24;26(5):e5080.

16 Raaijmakers A, Petit T, Gu Y, Zhang Z, Wei F, Cools B, et al.: Design and feasibility of "PREMATurity as predictor of children's Cardiovascular - renal Health" (PREMATCH): A pilot study. Blood Press. 2015;24(5):275-83.

17 Haycock GB, Schwartz GJ, Wisotsky DH. Geometric method for measuring body surface area: a height-weight formula validated in infants, children, and adults. J Pediatr. 1978 Jul;93(1):62-6.

18 Village G; National High Blood Pressure Education Program Working Group on High Blood Pressure in Children and Adolescents. The fourth report on the diagnosis, evaluation, and treatment of high blood pressure in children and adolescents. Pediatrics. 2004 Aug;114(2 Suppl 4th Report):555-76.

19 Kułaga Z, Litwin M, Tkaczyk M, Palczewska I, Zajączkowska M, Zwolińska D, et al. Polish 2010 growth references for school-aged children and adolescents. Eur J Pediatr. 2011 May;170(5):599-609.

20 Li J, Dunn W, Breaud A, Elliott D, Sokoll LJ, Clarke W. Analytical performance of 4 automated assays for measurement of cystatin C. Clin Chem. 2010 Aug;56(8):1336-9. 
21 Grubb A, Horio M, Hansson L, Björk J, Nyman U, Flodin M, et al.: Generation of a New Cystatin C-Based Estimating Equation for Glomerular Filtration Rate by Use of 7 Assays Standardized to the International Calibrator. Clin Chem. 2014 Jul;60(7):974-86.

22 Dinkel E, Ertel M, Dittrich M, Peters H, Berres M, Schulte-Wissermann H. Kidney size in childhood. Sonographical growth charts for kidney length and volume. Pediatr Radiol. 1985;15(1):38-43.

23 Roos JF, Doust J, Tett SE, Kirkpatrick CM. Diagnostic accuracy of cystatin C compared to serum creatinine for the estimation of renal dysfunction in adults and children - a meta-analysis. Clin Biochem. 2007 Mar;40(5-6): 383-91.

24 Rodríguez-Soriano J, Aguirre M, Oliveros R, Vallo A. Long-term renal follow-up of extremely low birth weight infants. Pediatr Nephrol. 2005 May;20(5):579-84.

25 Rakow A, Johansson S, Legnevall L, Sevastik R, Celsi G, Norman M, et al. Renal volume and function in schoolage children born preterm or small for gestational age. Pediatr Nephrol. 2008 Aug;23(8):1309-15.

26 Wetzels JF, Kiemeney LA, Swinkels DW, Willems HL, den Heijer M. Age- and gender-specific reference values of estimated GFR in Caucasians: the Nijmegen Biomedical Study. Kidney Int. 2007 Sep;72(5):632-7.

27 Luyckx VA, Perico N, Somaschini M, Manfellotto D, Valensise H, Cetin I, et al.; writing group of the Low Birth Weight and Nephron Number Working Group. A developmental approach to the prevention of hypertension and kidney disease: a report from the Low Birth Weight and Nephron Number Working Group. Lancet. 2017 Jul;390(10092):424-8.

28 Barker DJ, Osmond C, Golding J, Kuh D, Wadsworth ME. Growth in utero, blood pressure in childhood and adult life, and mortality from cardiovascular disease. BMJ. 1989 Mar;298(6673):564-7.

29 Pharoah PO, Stevenson CJ, West CR. Association of blood pressure in adolescence with birthweight. Arch Dis Child Fetal Neonatal Ed. 1998 Sep;79(2):F114-8.

30 Keijzer-veen MG, Dülger A, Dekker FW, Nauta J, van der Heijden BJ. Very preterm birth is a risk factor for increased systolic blood pressure at a young adult age. Pediatr Nephrol. 2010 Mar;25(3):509-16.

31 Vohr BR, Allan W, Katz KH, Schneider KC, Ment LR. Early predictors of hypertension in prematurely born adolescents. Acta Paediatr. 2010 Dec;99(12):1812-8.

32 Lurbe E, Carvajal E, Torro I, Aguilar F, Alvarez J, Redon J. Influence of Concurrent Obesity and Low Birth Weight on Blood Pressure Phenotype in Youth. Hypertension. 2009 Jun;53(6):912-7.

33 Kistner A, Celsi G, Vanpee M, Jacobson SH. Increased blood pressure but normal renal function in adult women born preterm. Pediatr Nephrol. 2000 Dec;15(3-4):215-20.

34 Bayrakci US, Schaefer F, Duzova A, Yigit S, Bakkaloglu A. Abnormal circadian blood pressure regulation in children born preterm. J Pediatr. 2007 Oct;151(4):399-403

35 Hovi P, Andersson S, Räikkönen K, Strang-Karlsson S, Järvenpää AL, Eriksson JG, et al. Ambulatory blood pressure in young adults with very low birth weight. J Pediatr. 2010 Jan;156(1):54-59.e1.

36 Doyle LW, Faber B, Callanan C, Morley R. Blood pressure in late adolescence and very low birth weight. Pediatrics. 2003 Feb;111(2):252-7.

37 Pyhälä R, Räikkönen K, Feldt K, Andersson S, Hovi P, Eriksson JG, et al. Blood pressure responses to psychosocial stress in young adults with very low birth weight: helsinki study of very low birth weight adults. Pediatrics. 2009 Feb;123(2):731-4.

38 Gupta-Malhotra M, Banker A, Shete S, Hashmi SS, Tyson JE, Barratt MS, et al. Essential hypertension vs. secondary hypertension among children. Am J Hypertens. 2015 Jan;28(1):73-80.

39 Keijzer-Veen MG, Devos AS, Meradji M, Dekker FW, Nauta J, van der Heijden BJ. Reduced renal length and volume 20 years after very preterm birth. Pediatr Nephrol. 2010 Mar;25(3):499-507. 